\title{
EL USO DE SUBTÍTULOS PASIVOS Y ACTIVOS EN LA ENSEÑANZA DE LENGUAS EXTRANJERAS: UNA REVISIÓN DE LAS POSIBILIDADES DIDÁCTICAS DE AMBOS RECURSOS
}

\author{
The Use of Passive and Active Subtitles in Foreign Language Teaching: A View \\ to their Teaching Potential \\ L'UTILISATION DES SOUS-TITRES PASSIFS ET ACTIFS POUR L'ENSEIGNEMENT DES LANGUES \\ ÉTRANGÈRES : UN RETOUR SUR LEUR POSSIBILITÉS DIDACTIQUES
}

\author{
Gloria Torralba-Miralles \\ Doctora en Traducción, Sociedad y \\ Comunicación, Universitat Jaume I. \\ Profesora asistente, Departament \\ d'Educació, Facultat de Ciències \\ Humanes i Socials, Universitat Jaume I. \\ Campus del Riu Sec, E-1 2071 \\ Castelló de la Plana (España) \\ gloria.torralba@uji.es \\ https://orcid. \\ org/0000-0002-7019-4504
}

\begin{abstract}
RESUMEN
Tras años de rechazo y críticas que vinculaban su aspecto lúdico a posibles distracciones dentro del aula, en las últimas décadas la traducción audiovisual ha sido aceptada como una herramienta para el aprendizaje de lenguas. Las necesidades reales han demostrado que el visionado de productos audiovisuales subtitulados ayuda en la adquisición y el perfeccionamiento de lenguas y que por tanto tiene cabida en las aulas. Recientemente, se ha dado un paso más en la explotación de este recurso pasando de los subtítulos pasivos a los activos, y convirtiendo al agente receptor, en este caso, el estudiante de lengua extranjera, en agente subtitulador. En este artículo, se exponen las categorías más comunes y cómo se trabaja con cada una de ellas, se realiza una revisión de las posibilidades didácticas de ambas actividades, se analizan los beneficios de la subtitulación activa y se presentan algunos programas de subtitulación que posibilitan el uso de esta herramienta didáctica.
\end{abstract}

Palabras claves: aprendizaje de lenguas; lenguas extranjeras; subtitulación pasiva; subtitulación activa; traducción audiovisual.

\begin{abstract}
After years of rejection and criticism blaming on their entertaining nature as a source of distraction within the classroom, in recent decades audiovisual translation has been accepted as a tool for language learning. Real-life needs have shown that watching subtitled audiovisual materials enhances language acquisition and foster varied skills, so that it has gained a place in the classroom. Recently, one step forward has been taken in the use of this resource, moving from passive subtitles to active subtitling, in order to turn the target receiver - the foreign-language student - into a subtitler. The present article presents the most common categories and explains how to work with them, looks at the didactic possibilities of both activities, analyses the benefits of active subtitling, and presents some subtitling programmes whose features make them feasible for use as a teaching tool.
\end{abstract}

Received: 2018-05-03 / Accepted: 2019-07-22 / Published: 2020-01-28

http://www.doi.org/10.17533/udea.ikala.v25n01a11 
Keywords: language learning; foreign languages; passive subtitling; active subtitling; audiovisual translation.

\section{RESUMÉ}

Après avoir critiqué l' aspect ludique et distracteur de la traduction audiovisuelle et l'avoir écartée de la salle de classe, les dernières décennies l'ont vue finalement acceptée comme un outil didactique pour l'apprentissage des langues. Les nouvelles réalités ont montré que visualiser des produits audiovisuels sous-titrés aide à l'acquisition et à l'amélioration de l'apprentissage des langues et donc leur utilisation didactique est pertinente. Récemment, le passage des sous-titres passifs aux sous-titres actifs convertit l'agent récepteur, l'étudiant d'une langue étrangère, en agent qui sous-titre. Dans cet article, nous envisageons les possibilités didactiques de ces deux activités. Nous en proposons les catégories les plus courantes et les différentes activités qu'elles permettent. Nous analysons ensuite les avantages du sous-titrage actif et présentons des programmes de sous-titrage qui rendent possible son utilisation comme un outil didactique.

Mots clés : apprentissage de langues ; langues étrangères ; sous-titrage actif; sous-titrage passif; traduction audiovisuelle. 


\section{Introducción}

Hoy en día pocas personas niegan la ayuda de los subtítulos presentes en diferentes productos audiovisuales para lograr un mayor dominio de una lengua extranjera $(\mathrm{LE})^{1}$, en concreto, el inglés, por tratarse de uno de los idiomas más estudiados en los centros educativos. De hecho, es muy habitual que cuando se habla del elevado nivel de conocimiento de este idioma en algunos países del norte de Europa, cuya lengua oficial no es el inglés, se atribuya a la tradición subtituladora de esta región, a pesar de que esta no sea la única ni siquiera la principal causa (Chaume, 2004). Esto ha conllevado a que cada vez sean más numerosas las voces en países dobladores que abogan por la supresión del doblaje como solución para los bajos niveles de suficiencia en inglés entre sus ciudadanos.

A pesar de esta corriente de aceptación, e incluso, podríamos decir, de defensa a ultranza de los subtítulos, estos no siempre han disfrutado de esta condición de recurso "óptimo" para el aprendizaje deidiomas. De hecho, apenas un par de décadas atrás, esta modalidad de traducción audiovisual encontraba gran resistencia entre los académicos del campo de la didáctica de las lenguas, pues veían los textos audiovisuales, subtitulados o no, como un elemento distractor dentro del aula y se resistían a aceptar que un material tan relacionado con el entretenimiento, especialmente aquellos productos audiovisuales creados básicamente para recrear al espectador, pasaran a ser un objeto central de la clase de lengua extranjera.

Aun así, en las últimas décadas, diversas voces han empezado a abrir las puertas de las aulas a textos audiovisuales reales, es decir, creados con un objetivo distinto al didáctico. Estos textos en lengua extranjera pueden presentar problemas de comprensión entre receptores que no cuenten con un nivel suficiente de conocimientos lingüísticos, por ello a menudo van acompañados de subtítulos que faciliten su entendimiento.

1 Siguiendo las recomendaciones de las investigaciones que versan sobre el bilingüismo, utilizaremos la nomenclatura "lengua extranjera (LE)" para distinguirla de "segunda lengua (L2)”.

\section{Aprender lenguas desde la recepción}

Uno de los primeros en demostrar que los subtítulos no son una fuente de distracción ni de apatía, sino que tienen un gran potencial como herramienta en el aprendizaje de lenguas fue Robert Vanderplank (1988, p. 272). Este potencial, señala el autor, se debe en gran medida a que los productos audiovisuales subtitulados proporcionan grandes cantidades de información real y comprensible. La importancia del input llevó a Vanderplank a relacionar las obras audiovisuales acompañadas de subtítulos con dos principios de Krashen (1982) en los cuales él justifica su uso en las clases de lengua extranjera, a saber, la hipótesis de información de entrada y del filtro afectivo.

Por un lado, en la hipótesis de información de entrada (input hypothesis) (Krashen, 1982) se defiende que la información que recibe el alumnado tiene que ser comprensible y superar ligeramente su nivel de competencia, puesto que así se estimula el entusiasmo por el aprendizaje. Krashen (p. 20) enfatiza la oposición de esta hipótesis frente a las ideas imperantes, las cuales defendían que la fluidez en un idioma se conseguía después de haber aprendido unas estructuras y haber empezado a hacer uso de ellas. Es cierto que hasta nuestros días esta creencia ha sido aceptada por muchas instituciones académicas y corrientes pedagógicas, a cuyos miembros y seguidores les costaba aceptar que los estudiantes pudieran avanzar en su formación si no dominaban conceptos gramaticales básicos. Es justo este dominio el que Krashen ve innecesario. En la defensa de su hipótesis, el autor argumenta que la adquisición de una lengua se produce cuando se intentan comprender estructuras de un nivel superior al ya adquirido; $y$ añade que esto se consigue con la ayuda del contexto o de información extralingüística. La explicación de esta hipótesis, y más todavía si lleva implícita cierta inconsciencia en el proceso de adquisición de una lengua, se puede ligar fácilmente al uso de material audiovisual en lengua extranjera.

La abundancia de información extralingüística que contiene un texto audiovisual, lo que Chaume (2003, p. 90) denomina códigos sígnicos, que incluyen, además de los lingüísticos, los paralingüísticos, 
los musicales, los icónicos o los efectos especiales, entre otros, es fundamental para entender un vídeo en una lengua extranjera que no se domina.

Por otro lado, la hipótesis del filtro afectivo (affective filter hypotesis) (Krashen, 1982, p. 30) la usa Krashen para señalar la posible relación con la adquisición de lenguas extranjeras cuando la conecta con factores como la motivación, la confianza en uno mismo y la ansiedad. El filtro afectivo sería un mecanismo que define la predisposición a adquirir un idioma por parte del alumnado. Así, si el filtro afectivo está en un nivel alto, el estudiante se sentirá desmotivado o ansioso; mientras que, si el filtro está bajo, el estudiante no se preocupará por la posibilidad de fracasar e, incluso, puede sentirse tan involucrado en el mensaje que llegue a olvidar que está escuchando o leyendo otra lengua (Krashen, 1987, p. 66). De nuevo podemos aplicar esta hipótesis al uso del material audiovisual en las clases, en gran medida por su valor lúdico. El propio Krashen subraya la importancia de que el profesorado de lengua imparta clase en un ambiente con un nivel de ansiedad bajo y, en este sentido, la presencia del audiovisual, un elemento tan habitual en nuestras vidas hoy en día, puede contribuir a la hora de mantener bajo el filtro afectivo.

Vanderplank (1988, p. 277) también adopta la hipótesis del filtro afectivo para defender el uso de los subtítulos como herramienta didáctica, apuntando a la utilidad del texto, en este caso en forma de subtítulos, como elemento que da seguridad al estudiantado. El autor se refiere a los subtítulos de Ceefax, el teletexto del Reino Unido, consumidos por estudiantes extranjeros de intercambio para mejorar sus niveles de inglés, y defiende que el "feedback instantáneo" refuerza el aprendizaje y la confianza de los alumnos.

Después de Vanderplank, han sido diversos los autores y estudios (Araújo, 2008; Bianchi, 2015; BolañosGarcía-Escribano, 2017; Danan, 2004; Gernsbacher, 2015; Koolstra y Beentjes, 1999; Incalcaterra McLoughlin y Lertola, 2014; Lertola, 2012, 2013; Lopriore y Ceruti, 2015; Neuman y Koskinen, 1992; Pavakanun y d'Ydewalle, 1992; Talaván,
2010, 2011, 2013 o Williams y Thorne, 2000) que han demostrado los beneficios de consumir programas audiovisuales subtitulados y han confirmado que cada uno de los distintos tipos de subtitulación existentes resulta idóneo en niveles de conocimiento diferentes y para fortalecer aspectos lingüísticos también diversos. En lo que la mayoría coincide es en que la subtitulación, además de contar en general con una buena acogida por parte del alumnado (Gómez Pérez y Roales Ruiz, 2011), efectivamente activa conocimientos lingüísticos que se han adquirido en algún momento y ayuda a practicar, mantener y ampliar el nivel de competencia (Díaz-Cintas, 2012, p. 104).

\section{Un tipo de subtítulo para cada habilidad lingüística}

En los años ochenta y noventa, varios autores empezaron a estudiar las diferentes aplicaciones que tenían los subtítulos como herramienta para el aprendizaje de lenguas. Si bien es habitual relacionar "subtitulación" con subtítulos interlingüísticos directos (imágenes en LE y subtítulos en L1, o lengua materna), lo cierto es que las primeras investigaciones sobre la función pedagógica de la subtitulación se llevaron a cabo con los subtítulos para sordos o SPS (intralingüísticos, imágenes y subtítulos en la misma lengua), los cuales ya eran comunes en muchos países hacía más de tres décadas. Así, por ejemplo, en Estados Unidos, en los ochenta, empezaron a surgir estudios sobre la aplicación de lo que ellos denominan subtítulos cerrados o CCTV (closed captioned $T V$ ) en la enseñanza de lenguas.

Hay que destacar también que, a pesar de que los principales receptores de este tipo de subtítulos son las personas sordas, los inmigrantes - cuya presencia era fuerte en los Estados Unidos ya en aquella épocalos utilizaban como refuerzo para entender el audio. Esta función didáctica favoreció la aparición de estudios como el de Parlato (1986) quien, después de realizar ejercicios con estudiantes sordos, relacionó el consumo de programas subtitulados con la fluidez lectora y el conocimiento metalingüístico sobre cómo utilizar la lengua. 
Otros autores también observaron la utilidad de la sps no solo en personas sordas, sino también en estudiantes de lengua extranjera. Así, Todd Ellsworth (1992) y Tim Rees (1993), profesores de inglés como segunda lengua, comprobaron que sus alumnos mejoraban el vocabulario y la comprensión oral tras ver programas subtitulados, además de que aumentaban sus conocimientos sobre la cultura estadounidense. Pocos años después, Huang y Eskey (1999) incidían en este aprendizaje sociocultural y, a la vez, recordaban que más de la mitad de los consumidores de SPS en realidad eran oyentes y que, por lo tanto, algunas de las habilidades más susceptibles de mejora con los subtítulos para sordos son justamente la comprensión oral y las habilidades comunicativas.

Es de resaltar que el formato de estos subtítulos también resulta un elemento clave en el proceso de aprendizaje, pues la aparición en pantalla de toda la información paralingüística que necesita el espectador sordo para entender el argumento resulta a la vez una fuente continua de vocabulario más descriptivo y, por lo tanto, bastante útil para quienes están empezando a conocer una lengua y una cultura extranjeras. Si bien a estos subtítulos se les ha encontrado una aplicación didáctica, lo cierto es que no están concebidos con esta finalidad. No pasa lo mismo con el otro tipo de subtítulos intralingüísticos, los bimodales, también con sonido y texto en LE, pero sin información paralingüística, los cuales se denominan "subtítulos didácticos per se” (Díaz-Cintas, 2012, p. 101).

Gambier (2007) hace una compilación de los primeros estudios llevados a cabo con subtítulos intralingüísticos (Baltova, 1999; Bean y Wilson, 1989; Borrás y Lafayette, 1994; Danan, 1992; Garza, 1991; Goldman y Goldman, 1988; Koskinen, Knable, Markham, Jensema y Kane, 1996; Markham, 1989; Neuman y Koskinen, 1992; Vanderplank, 1988) y destaca sus beneficios para la memorización y el aprendizaje del vocabulario, así como para el desarrollo de la expresión oral y escrita. Por otra parte, Vanderplank (2016) ha realizado más recientemente otra recopilación en la que reflexiona sobre el desarrollo del aprendizaje de lenguas basado en la subtitulación en los últimos treinta años.

De hecho, en el siglo XXI han seguido surgiendo estudios basados en este tipo de subtitulación que investigan la influencia de los subtítulos en la mejora de varios aspectos lingüísticos, como la adquisición de vocabulario (Bird y Williams, 2002; Winke, Gass y Sydorenko, 2010), el desarrollo de la comprensión oral y escrita (Caimi, 2006) y la mejora de la comprensión y la expresión orales (Knable, Markham, Jensema y Kane, 2008).

Resultan, además, una robusta base científica aquellos trabajos llevados a cabo en el campo de la psicolingüística, dado que demuestran la importancia de la visualización fonológica de los elementos oralizados. Algunos de estos primeros trabajos se llevaron a cabo con niños (d'Ydewalle y van Rensbergen, 1989; Lambert y Holobow, 1984), lo que ha dado pie a la aparición de nuevos parámetros básicos para medir la adecuación de esta herramienta en el aula de lengua extranjera. Se trata de factores como el hábito en el visionado de productos subtitulados, el cual está relacionado también con la tradición subtituladora de la región donde vive o de donde proviene el espectador; o la facilidad lectora de este, la cual en el caso de los más pequeños será directamente proporcional a la edad. De hecho, algunos autores han recordado que la mejora en la comprensión puede estar más relacionada con la capacidad lectora que con la comprensión oral (Caimi, 2006; Diao, Chandler y Sweller, 2007; Winke et al., 2010). Marzà y Torralba (2015) apuntan a estos factores en su trabajo sobre la aceptación de subtítulos entre los niños y suman la importancia de escoger material adecuado, hecho que recordaba también Gambier (2007, p. 105) cuando alertaba que una exposición masiva a programas mal seleccionados podría convertir estos productos en una herramienta pedagógica inapropiada.

Para terminar, cabe recordar la importancia de la subtitulación bimodal ya mencionada como herramienta alfabetizadora y fomentadora del hábito lector en niños, tal como han demostrado las investigaciones de Kothari y Bandyopadhyay $(2011,2014)$ y Kothari, 
Pandey y Chudgar (2004) en la India. Gambier (2007) también clasifica los subtítulos inversos (audio en L1 y subtítulos en LE) como destinados a priori a la enseñanza de una lengua. De hecho, esta clase de subtitulación no es demasiado común y precisamente son muchos los espectadores interesados en lenguas que reclaman tener esta opción en las nuevas plataformas televisivas. Esta modalidad se ha encontrado con dos tipos de objeciones.

La primera está relacionada con la reticencia de algunos a permitir la presencia de la lengua materna dentro del aula, a pesar de que varios expertos han demostrado el papel didáctico tanto de la L1 como de las transferencias L1-LE (Cook, 2001; Cummins, 2007; Malmkjaer, 1998). La segunda también tiene que ver con la L1 y los inconvenientes que puede causar en el proceso de aprendizaje el hecho de que el estudiante escuche los diálogos en una lengua que domina y, por lo tanto, no necesite la ayuda de los subtítulos. Aun así, si bien es cierto que la comprensión oral sería una habilidad que no se trabajaría en estos casos, está demostrado que, ante la aparición de subtítulos, el espectador los lee de manera inevitable (d'Ydewalle, Muylle y Van Rensbergen, 1985; d'Ydewalle y Gielen, 1992, pp. 416-417) y que la combinación de la información que llega por los dos canales facilita el aprendizaje de léxico en LE (Danan, 1992; Lambert, Boehler y Sidoti, 1981). Es más, dado que este tipo de subtítulos suelen consumirlos personas que quieren aprender una lengua y que, por lo tanto, los usan de manera plenamente consciente, se podría decir que son el ejemplo más claro de que no constituyen un elemento distractor. Más bien al contrario: el espectador centra la mayor parte de la atención en el código escrito, puesto que entender la información que le llega por el canal oral no le supone prácticamente ningún esfuerzo.

Los subtítulos interlingüísticos estándares, en los cuales el audio está en LE y los subtítulos en L1, son los más comunes cuando se trata de productos audiovisuales creados con el objetivo principal de entretener al espectador. Este aspecto lúdico ha hecho que la mayoría de expertos relacionen la subtitulación estándar con la adquisición, y no con la enseñanza, de LE, es decir, con aquella que se produce de una manera incidental, sin tener que hacer un esfuerzo consciente (Koolstra y Beentjes, 1999; Pavakanun y d'Ydewalle, 1992), y en la cual la motivación resulta fundamental (Ryan, 1998). Con este tipo de subtítulos sucede algo parecido a lo que ocurre con los inversos: la presencia de la lengua materna despierta las críticas de sus detractores, quienes creen que el espectador centra más su atención en leer los subtítulos que en escuchar el audio, hecho que le supone un mayor esfuerzo. Sin embargo, estudios recientes como el de Danan (2004) recuerdan que es justamente esta presencia de la L1 lo que anima a los espectadores a consumir material subtitulado, sobre todo si sus conocimientos de LE son limitados y los subtítulos bimodales pueden resultar demasiado complicados si no están debidamente seleccionados. Es por este motivo que últimamente se ha establecido el uso de estos subtítulos para los niveles iniciales, mientras que los bimodales se reservan para estadios más avanzados (Araújo, 2008).

Trabajos como los llevados a cabo por Koolstra y Beentjes (1999) y Pavakanun y d'Ydewalle (1992) demuestran que los subtítulos tradicionales son una buena herramienta para adquirir léxico en LE. Danan (2004, p. 72) cree que esta mayor adquisición de conocimientos léxicos se produce por la conexión que hace el espectador entre las palabras que escucha en una lengua y su forma escrita, que lee en otra. Es el hecho de recibir una misma información en dos códigos lingüísticos diferentes lo que provoca que el proceso de retención sea mayor. Cabe destacar, por otra parte, que estudios recientes como el de BirulésMuntané y Soto-Faraco (2016) no han encontrado grandes diferencias en cuanto a la adquisición de vocabulario después de comparar el visionado de subtítulos en lengua extranjera (inglés) y L1 (español). Sin embargo, los resultados son mejores en el primer caso cuando se evalúan las habilidades lingüísticas y en el segundo en lo que se refiere a la comprensión del texto audiovisual.

\section{La subtitulación como herramienta didáctica: el aprendizaje activo}

Tal como hemos visto, son numerosos los estudios empíricos que demuestran la validez del material audiovisual subtitulado en el aprendizaje de lenguas 
extranjeras. Hoy en día pocos dudan del relevante papel que puede jugar esta modalidad de traducción audiovisual en la didáctica de lenguas e incluso es común que en los hogares los padres y las madres sintonicen programas infantiles en versión original subtitulada para que sus hijos e hijas vayan acostumbrándose a escuchar una lengua extranjera, normalmente el inglés.

La realidad es que el principal acercamiento a la subtitulación, tanto en las aulas como fuera de ellas, se ha llevado a cabo desde una perspectiva pasiva, es decir, como meros consumidores de subtítulos. Hasta los últimos años, habían sido muy pocos los investigadores interesados en utilizar la subtitulación como tarea activa, dicho de otro modo, en involucrar a los estudiantes en la traducción y subtitulación de material audiovisual. Díaz-Cintas (1995) fue de los primeros en llamar la atención sobre las posibilidades didácticas de la subtitulación más allá de las aulas de traducción. En su estudio, el autor repasa aspectos lingüísticos que deben tenerse en cuenta a la hora de realizar la tarea traductora, a la cual tilda sin tapujos de "actividad tan común para el aprendizaje de idiomas" (Díaz-Cintas, 1995, p. 14). Además, enumera distintas características propias del género audiovisual, como son su carácter lúdico y motivador, que favorecen su presencia en las aulas.

Este primer acercamiento a la subtitulación activa como herramienta para el aprendizaje de lenguas fue recogido en los años posteriores por autoras como Talaván (2006), Vermeulen (2003) o Wagener (2006), quienes abogaban por dejar atrás un aprendizaje pasivo y receptivo y buscar una metodología basada en la independencia y el papel activo del estudiantado.

El potencial de la subtitulación activa ha quedado demostrado en trabajos empíricos como los de Araújo (2008), Lertola (2012) o Talaván (2010, 2011), quienes han evidenciado no solo el gran atractivo que esta tarea ejerce entre los estudiantes, sino también su utilidad en el desarrollo de diferentes habilidades lingüísticas. La prueba de que la subtitulación puede encontrar su lugar fuera de las aulas de traducción se halla en el hecho de que todas estas investigaciones se realizaron en clases de lengua extranjera, ya fuera con estudiantes de escuelas de idiomas o universitarios que realizaban algún curso de lengua.

Además, ha quedado demostrado que la tarea de subtitular puede incluir varios aspectos didácticos que van más allá del mero aprendizaje lingüístico. Talaván y Ávila-Cabrera recogen los más significativos:

\section{Subtitling as an active learning task is a very attrac- tive activity for different types of learners: people keen on cinema, original version videos, translation, subtitles, ICT [information and communication tech- nologies] and other multimedia materials. This AVT [audiovisual translation] mode used as a didactic re- source obviously enhances task-based learning, situating the class within an authentic, active, familiar and moti- vating context. Furthermore, it fosters both autonomous and collaborative learning, since it can be performed in- dividually or in small groups. (Talaván y Ávila-Cabrera, 2015, pp. 150-151)}

Además, la presencia del elemento audiovisual suele, como mínimo, captar la atención de quienes no creen en absoluto en las posibilidades pedagógicas de la traducción. Cuando se trata de utilizar un vídeo como un texto, el profesorado suele ser consciente de que cuenta con una gran ventaja, como bien describe Neves:

The magical enchantment of the moving image, the attraction of working with computers and electronic equipment and, above all, the fun element, makes tiresome tasks light and makes language learning pleasurable. (2004, p. 38)

\section{Trabajar el lenguaje desde la producción}

Como hemos visto, los primeros años del siglo XXI marcaron un cambio en el uso de la subtitulación como herramienta para el aprendizaje de lenguas. La proliferación de estudios teóricos y prácticos demostraba que esta modalidad de traducción audiovisual se podía trabajar desde otras vertientes diferentes al simple visionado seguido de ejercicios basados en aquello que se había observado en la pantalla. Tal como pasaba con los subtítulos explotados desde un punto de vista pasivo, cada una de las modalidades 
subtituladoras puede convertirse en un recurso de aprendizaje, siempre dependiendo del nivel de lengua del alumnado y de las habilidades que se quieran trabajar.

Hay que tener presente que la traducción intralingüística no implica una traducción en sí, sino una reformulación de aquello dicho. En el caso de la subtitulación, la transcripción condensada del guion exige al alumnado "alejarse" del texto origen y es una actividad muy recurrente en las primeras fases de formación de traductores, donde es habitual traducir "palabra por palabra”. Lertola (2015) y Talaván, Lertola y Costal (2016) trasladan estas mismas actividades al aula de lengua extranjera con el objetivo de trabajar la comprensión y la capacidad de resumir y parafrasear. Este tipo de ejercicios obliga a los estudiantes a ampliar su vocabulario, dado que las características específicas del formato del subtítulo a menudo los obligan a buscar sinónimos o reformular frases con el fin de transferir la misma información de una manera diferente. La conveniencia de un buen dominio de la lengua para llevar a cabo estas tareas hace recomendable realizar las subtitulaciones intralingüísticas en LE con estudiantes que presentan un nivel de lengua alto. Hay que recordar también que los subtítulos para sordos, que suelen implicar una traducción intralingüística, son un buen recurso dada la presencia de elementos paralingüísticos que favorecen la práctica léxica.

Los subtítulos interlingüísticos, aquellos que implican una traducción per se, son los más habituales en las clases de LE y se pueden trabajar en ambas direcciones: directa $(\mathrm{LE} \rightarrow \mathrm{L} 1)$ o inversa $(\mathrm{L} 1 \rightarrow \mathrm{LE})$, dependiendo del nivel de lengua del alumnado y de los aspectos lingüísticos que se quieran trabajar. Del mismo modo que la opción de subtitulación estándar (audio en LE y subtítulos en L1), la subtitulación directa es la más consumida por los espectadores; también ha sido la más utilizada en los estudios empíricos llevados a cabo hasta hoy. De hecho, son pocas las investigaciones en las cuales se ha realizado una subtitulación inversa, probablemente porque los investigadores son conscientes de las dificultades que comporta una traducción hacia una lengua extranjera si los sujetos no cuentan con una buena competencia lingüística. Carreres (2006, p. 5) recoge algunas ideas en contra de la traducción inversa como, por ejemplo, que es una actividad contraproducente, porque obliga al estudiantado a observar la LE a través del prisma de la L1, hecho que ocasiona interferencias y bloquea la expresión libre en la lengua que se está aprendiendo.

A pesar de esto, hay que tener en cuenta que la traducción inversa es un recurso magnífico para desarrollar la expresión escrita en LE, habilidad que no se trabaja en la modalidad directa. Esto queda demostrado en algunas de las pocas investigaciones que se han llevado a cabo con la subtitulación inversa desde un punto de vista activo: Talaván y Rodríguez-Arancón (2014) y Talaván, Ibáñez y Bárcena (2017) presentan tareas guiadas de subtitulación activa con estudiantes de inglés, cuya implantación conllevó evidentes mejoras en la expresión escrita y en las distintas habilidades traductológicas. Burczyńska (2015), por su parte, apunta a una combinación de este tipo de ejercicios - con los que trabajar la gramática y la adquisición de vocabulario informal-, con el uso de libros de texto, a los que se recurre a la hora de aprender léxico formal.

En líneas generales, como decíamos, se suele coincidir en que la traducción directa es un procedimiento más natural y adecuado para los primeros niveles de aprendizaje, mientras que la inversa, que implica un mayor grado de exigencia y resulta útil para el aprendizaje de elementos culturales (Yuste Frías, 2005; Borghetti y Lertola, 2014), es más recomendable con estudiantado que cuente con mayores recursos. Lertola (2013, p. 200), por su parte, cree que la traducción directa es una actividad más útil de cara a detectar los problemas y errores traductológicos más comunes, ya que se exige una redacción en la $\mathrm{L} 1$; mientras que la inversaresulta más adecuada desde un punto de vista pedagógico, pues la expresión escrita se lleva a cabo en la LE.

Así pues, a pesar de que estudios recientes apuestan por el uso de ambas direcciones en el mismo grupo de estudiantes (Reig Gascón, 2017), en 
la subtitulación estándar encontramos un mayor número de estudios y un amplio abanico de elementos sobre los cuales trabajar. Si hablamos de las habilidades lingüísticas básicas tradicionales, observamos que las primeras investigaciones se centraron en la comprensión oral (Talaván, 2010, 2011; Williams y Thorne, 2000), pero sin duda el nivel léxico ha sido uno de los que más bibliografía ha motivado, puesto que se han realizado estudios no solo relacionados con la adquisición de vocabulario (Lertola, 2012, 2013; Talaván, 2007; Torralba, 2016), sino también con la adquisición de expresiones idiomáticas (Bravo, 2008). Por su parte, Incalcaterra McLoughlin (2009) investigó la retención de vocabulario y sintaxis, así como la mejora de la pragmática.

Por otro lado, es interesante observar cómo la subtitulación activa ha pasado a considerarse una herramienta presente no solo en el aula de traducción audiovisual o de aprendizaje de lenguas, sino también en otras áreas como, por ejemplo, la formación de maestros (López Cirugeda y Sánchez Ruiz, 2013; Torralba, 2018) o la odontología (Kantz, 2015). Por último, cabe apuntar que son varios los estudios que combinan ejercicios de subtitulación con otras modalidades de traducción audiovisual, especialmente el doblaje o las voces superpuestas (Incalcaterra McLoughlin y Lertola, 2016; Lertola, 2019; Lertola y Mariotti, 2017).

\section{Beneficios de la subtitulación activa}

Autores como Díaz-Cintas (2012), Sokoli (2006) y, sobre todo, Talaván (2013) han recogido en sus trabajos los numerosos beneficios pedagógicos que puede aportar la subtitulación desde un punto de vista práctico. Los más significativos serían:

- El material con que se trabaja es auténtico. Los clips que el alumnado subtitula son fragmentos de productos audiovisuales que se han creado para ser comercializados y consumidos por el gran público. Por este motivo es muy importante que, a la hora de escoger el texto audiovisual, se tenga en cuenta no solo que el contenido lingüístico sea adecuado al nivel del alumnado, sino también que la acción dramática que se desarrolla pueda resultarles atractiva. Si bien es cierto que el componente audiovisual siempre juega un papel fundamental a la hora de asegurar la implicación de los estudiantes, esta será mayor cuando la escena que traduzcan presente algún aliciente, ya sea porque la situación les resulte cercana o porque pertenezca a un producto conocido por ellos.

- El hecho de trabajar con vídeos reales provoca que la actividad subtituladora sea realista, es decir, el alumno asumirá el rol del profesional o, cuando menos, de fansubber. Por otra parte, puesto que desde el principio se tiene claridad sobre el carácter no comercial de la actividad, se permite cierta flexibilidad en el cumplimiento de los parámetros de subtitulación (Díaz-Cintas y Muñoz, 2006, p. 50). Además, lo que en un primer momento es una actividad de aula, fácilmente se convierte en un conocimiento con varias aplicaciones fuera de esta, como puede ser subtitular canciones o series para compartirlas, siempre teniendo en cuenta las normativas legales.

- Además de los textos trabajados, otro elemento que suele resultar atractivo entre el alumnado es el uso de las tecnologías de la información y la comunicación (TIC). A pesar de que cabe apuntar que la aceptación de este elemento puede depender de varios factores, como los recursos disponibles en los centros académicos y en los hogares de los estudiantes, la franja de edad de los estudiantes o las características del software utilizado, el uso de herramientas multimedia se ha convertido en algo tan habitual en nuestras vidas en los últimos años que cada vez son menos quienes muestran reservas ante las nuevas tecnologías. En el caso concreto de la enseñanza de lenguas, la British Educational Communications and Technology Agency (Becta) asegura que las TIC pueden jugar un papel básico en la adquisición de habilidades lingüísticas, tal como recogen Sokoli, Zabalbeascoa y Fountana, quienes recuerdan algunos de sus beneficios:

More specifically, ICT contributes to the key FL skills of listening, speaking, reading and writing in a variety of ways, including access to a vast range of information and learning opportunities: personalized work rate as 
digital resources can be slowed and replayed repeatedly depending on individual needs; increased personal interest in FL by watching films in DVD format with subtitles and multiple audio tracks in different languages. (2011, p. 221)

- Las TIC también son un elemento clave en otro de los beneficios didácticos que ofrece la subtitulación: la posibilidad de trabajar de manera autónoma y también colaborativa. La tarea subtituladora puede realizarse individualmente, por parejas o en pequeños grupos. Por un lado, si el aula está equipada adecuadamente, el alumno tendrá la posibilidad de trabajar de manera individual, cosa que en algunos casos le permitirá una mayor concentración, un control de su ritmo de trabajo y un aprendizaje de la distribución del tiempo. Por otro lado, una de las fases más comunes en este tipo de ejercicios es cuando los alumnos interactúan entre ellos y comparten la tarea realizada con el resto de la clase (gran grupo), momento en que suele producirse un intercambio de impresiones que puede ir más o menos dirigido por el profe-

- Cuando se trabaja en grupo, el alumnado suele repartirse las tareas, lo que comporta los beneficios del aprendizaje colaborativo. Además, la subtitulación también fomenta el aprendizaje basado en tareas, puesto que el estudiante progresa en la adquisición de una competencia comunicativa mientras realiza la tarea principal de la actividad. En la subtitulación, por lo tanto, se cumple la máxima de “aprender haciendo" (task-based learning). Talaván defiende que, con este método, se adquiere un lenguaje real, puesto que lo aprendido en el aula tiene una aplicación inmediata fuera de ella:

Un enfoque comunicativo basado en tareas, como el utilizado aquí, ayuda tanto a profesores como a alumnos a progresar de actividades controladas basadas en el uso del vídeo (y subtítulos) en los visionados incluidos en la tarea, a semicontroladas (las discusiones orales), y de ahí, a actividades de tipo más libre (la subtitulación en clase y, posteriormente, fuera del aula) (2013, p. 122).

- Naturalmente, unas últimas ventajas, pero no por ello menos importantes, serían las relacionadas con la adquisición de habilidades lingüísticas concretas o de vocabulario, las cuales se desarrollarán en el siguiente apartado. Hay que añadir, además, las posibilidades que ofrece la subtitulación activa en cuanto a la ampliación del conocimiento de elementos extralingüísticos, como los referentes culturales, que están presentes en la práctica de la traducción audiovisual en general y refuerzan la idea de que la comunicación va más allá del simple trasvase de palabras.

\section{Aplicaciones didácticas de las convenciones de la subtitulación}

Tal como hemos comentado, a la hora de explicar y aplicar las normas de subtitulación en el aula de LE hay que tener en cuenta que los estudiantes muy probablemente nunca llegarán a subtitular de manera profesional (tampoco es el objetivo), ni tendrán que crear subtítulos para productos que conlleven un elevado grado de dificultad (multilingües, de temática o registro muy especializados, etc.), sino que se limitarán a trabajar fragmentos que incluyan aspectos que al profesorado le interese tratar.

A pesar de resultar una actividad atractiva, la subtitulación exige el desempeño de una serie de parámetros que no siempre son bien recibidos en ámbitos científicos que no están directamente relacionados con la traducción y la formación de traductores. Por lo tanto, si lo que se quiere es que esta modalidad encuentre su espacio en la didáctica de lenguas, resulta indispensable relacionar cada uno de estos parámetros con el desarrollo de diferentes habilidades lingüísticas.

A pesar de que son numerosas las convenciones recogidas en diferentes obras y manuales sobre subtitulación (Díaz-Cintas, 2010; Ivarsson, 1992; Karamitroglou, 1998), nosotros las hemos agrupado en cinco únicas categorías. Dado que el presente trabajo se centra en la función didáctica de la subtitulación activa, no resulta tan importante que el alumnado domine cada uno de los parámetros, como que estos puedan utilizarse como herramientas para aprender lengua. Es por esto que no ahondaremos en la puesta en práctica de cada una de las categorías desde un punto de vista 
profesional, sino que las presentamos brevemente para a continuación especificar qué aspectos lingüísticos se trabajarán cuando se apliquen durante el proceso de creación de subtítulos.

\section{Forma del subtitulo}

El parámetro referente al formato obliga a no dividir unidades de sentido lógicas, ni dejar al final de una línea ciertas partículas gramaticales como artículos o preposiciones, así como tampoco segmentar unidades de sentido formadas por verbo y complemento, ni formas verbales compuestas. Estas restricciones obligan al estudiantado a hacer una revisión más o menos consciente de la sintaxis, que lo lleva a detectar las diferentes unidades de sentido en el texto origen, es decir, primero tiene que analizar la estructura de la oración correspondiente para identificar las diferentes proposiciones $\mathrm{u}$ oraciones subordinadas que la conforman, y después decidir, siempre con el condicionante temporal, cuántos subtítulos y líneas ocupará el texto una vez traducido.

Desde el punto de vista de la didáctica de la lengua, esta tarea comporta una revisión de aspectos sintácticos y semánticos básicos pero fundamentales. Las líneas que conforman cada uno de los subtítulos no solo tienen que cumplir las normas referentes al formato, sino que su reescritura tiene que asegurar la lecturabilidad (readibility), es decir, la facilidad de comprensión del texto en base al estilo en que está escrito, y la legibilidad (legibility), que hace referencia a aspectos tipográficos y de impresión. Perego y Ghia (2011, p. 178) consideran que las nuevas tecnologías aseguran sin problemas la segunda, mientras que la primera resulta más difícil de conseguir puesto que intervienen diferentes aspectos como el estilo o la estructura del texto.

\section{Tiempo de permanencia en pantalla}

Otro factor que interviene en la comprensión lectora es el tiempo de permanencia de los subtítulos en pantalla. Las investigaciones sobre velocidad de lectura que se han llevado a cabo hasta el día de hoy han concluido que un espectador medio lee entre 150 y 180 palabras por minuto, es decir, unas 2 o 3 palabras por segundo. Este resultado llevó a la instauración general de la "regla de los cinco/seis segundos", según la cual un subtítulo de dos líneas (70 caracteres) se leerá sin problemas en cinco o seis segundos y uno de una línea (35 caracteres), en tres (Díaz-Cintas, 2010, p. 345; González-Iglesias, 2012, p. 23).

Este parámetro es justamente uno de los primeros que denotan la idoneidad de la subtitulación, puesto quela imposibilidad de lectura provocada por unos subtítulos que desaparecen de pantalla de manera muy rápida provoca rechazo del espectador. Por eso, se propone un aprendizaje colaborativo en el que el estudiantado comparta su trabajo con compañeros con el objetivo de comprobar si el espectador cuenta con tiempo suficiente para leer los subtítulos. Hay que decir, aun así, que en la aplicación de este parámetro no se tienen en cuenta factores como el hábito ni la edad. Pensamos que hay situaciones en que habría que diferenciar, como mínimo, si el espectador es adulto o infantil. Este sería el caso, por ejemplo, del profesorado de LE que prepare subtítulos para sus alumnos: si los receptores son niños de entre nueve y doce años, Marzà y Torralba $(2015$, p. 206) recomiendan líneas de treinta caracteres, entre siete y ocho caracteres por segundo y ampliar la permanencia en pantalla de los subtítulos de dos líneas completas hasta los siete segundos como máximo.

\section{Pautado y sincronización}

El pautado o localización hace referencia a la segmentación de los diálogos originales en unidades de subtitulación. Se recomienda dividir las intervenciones del guion original en unidades con cadencia rítmica aproximada de tres-cuatro segundos, además de respetar el tiempo de permanencia en pantalla y los cambios de plano. A la hora de pautar también hay que tener presente la sincronización temporal o isocronía, es decir, la entrada y salida de los subtítulos se tiene que corresponder con la enunciación de los diálogos. Los estudiantes suelen quejarse del tiempo que requiere una buena sincronización. Es por eso que algunos autores (Sokoli, 2006, p. 5; Talaván, 2013, p. 116) optan por presentar tareas 
con los códigos temporales ya incluidos. Aun así, nosotros consideramos que el proceso de sincronización también tiene su aplicación didáctica, porque en él se activa de manera simultánea la comprensión oral y la escrita, ya que el subtitulador tiene que escuchar varias veces el audio y asegurarse de que el inicio de la intervención oral coincida exactamente con la aparición en pantalla de su traducción escrita, de forma que el espectador lea y escuche los diálogos a la vez y sin mucho esfuerzo.

\section{Sintesis de la información}

Estrechamente ligada a la fase de pautado o localización está la de síntesis de la información, que presenta un mayor número de aplicaciones didácticas. El espectador no puede esperar leer en los subtítulos todo lo que está escuchando por el canal oral, puesto que la velocidad de habla no coincide con la de lectura; esto hace necesario que se realice cierta síntesis del texto origen (Romero-Fresco, 2009). El hecho de trabajar con o sin guion ofrece la posibilidad de dar especial relevancia a la comprensión escrita, en el primer caso, o a la oral, en el segundo. Estas opciones dependerán del nivel de LE que tengan los alumnos, puesto que en los niveles inferiores no contar con el apoyo del guion puede provocar cierta inquietud y, además, la falta de comprensión dificultaría sobremanera la tarea de traducción y de subtitulación. Por este motivo recomendamos trabajar con la transcripción de los diálogos y también con el apoyo de diferentes tipos de diccionarios (monolingües, bilingües, sinónimos, entre otros).

También es recomendable que el profesorado dé algunas directrices básicas de lo que es la traducción y, especialmente, la traducción audiovisual, ya que los estudiantes que no han tenido ningún tipo de contacto con la traducción como tarea suelen relacionar esta actividad con la metodología de la gramática-traducción, es decir, una transferencia interlingüística "palabra por palabra" y por lo general no son conscientes de los diferentes canales que se conjugan en un texto audiovisual, de forma que el papel del profesorado será primordial en las sesiones de presentación de la actividad.

No pasa lo mismo con la síntesis, ejercicio con el que los estudiantes suelen estar familiarizados, puesto que es un recurso habitual en las asignaturas de lengua. La condensación de la información implica mantener la información del texto original sin reproducir todo el contenido formal y esto resulta una actividad adecuada para trabajar la expresión escrita en lengua materna (subtitulación convencional) o en lengua extranjera (subtitulación inversa). El estudiantado no solo centrará su atención en reconocer los elementos redundantes o innecesarios que las normas de subtitulación recomiendan omitir (vocativos, nombres propios, interjecciones,

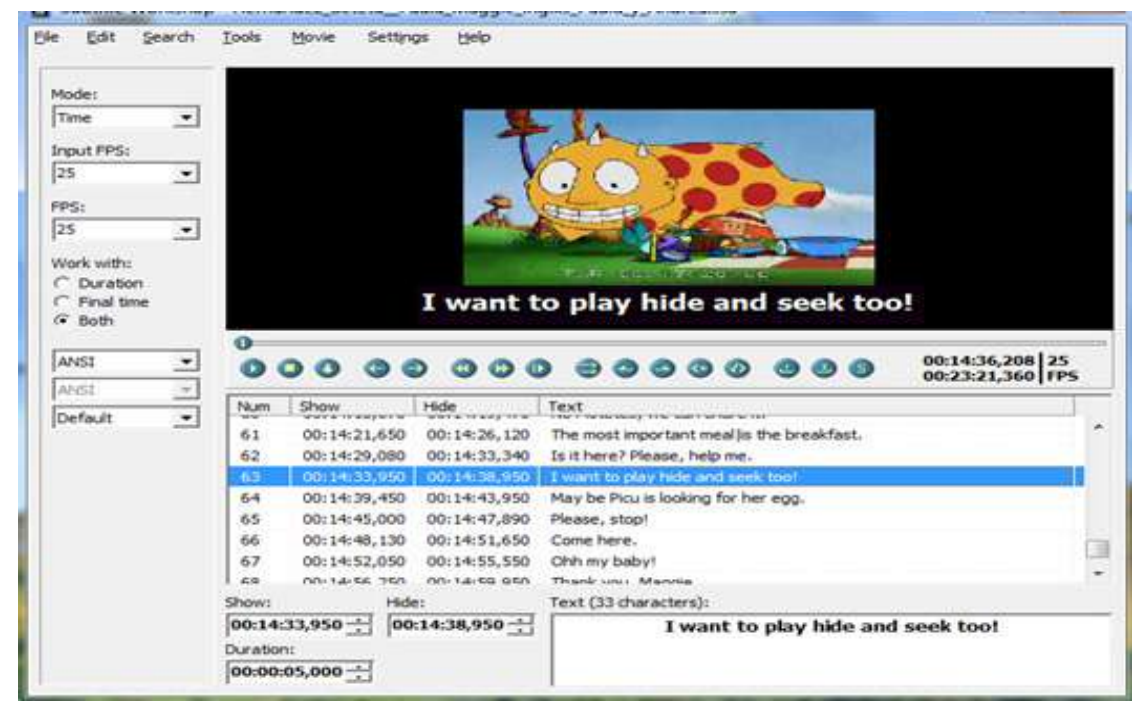

Figura 1 Interfaz de trabajo de Subtitle Workshop 
marcadores del discurso, perífrasis verbales), sino también otros que no son indispensables para la comprensión del mensaje, lo que le obligará a llevar a cabo resúmenes, paráfrasis o economía en la expresión (Neves, 2004). En relación con este parámetro, Lertola (2015, p. 255) recuerda la naturaleza digital de las nuevas generaciones de estudiantes, quienes están acostumbradas a recurrir a la condensación a la hora de comunicarse de manera virtual. Esta realidad puede resultar una desventaja puesto que hay que asegurar que el texto meta posibilite una comprensión lectora rápida y libre de problemas o interferencias gramaticales y léxicas, elementos que suelen estar presentes en el lenguaje utilizado en los mensajes de texto o las redes sociales. Por último, cabe subrayar que la necesaria reformulación para adecuarse a las restricciones espaciales obliga a buscar sinónimos que puedan condensar la información y esto se traduce en una mejora léxica.

\section{Convenciones ortotipográficas}

Finalmente, del mismo modo que en los subtítulos no se permite la laxitud estructural de los mensajes de texto, tampoco tienen cabida recursos que comporten economía espacial como abreviar palabras eliminando algunas letras u obviar signos de puntuación.
La aplicación didáctica de la ortotipografía en las clases de lengua permitirá, además de estudiar el uso de diferentes recursos tipográficos como la cursiva o las comillas, también revisar normas ortográficas básicas o de puntuación, aspecto clave para entender el significado de los enunciados en los pocos segundos que permanecen en pantalla (por ejemplo, las comas detrás de vocativo o el punto que marca el final de una frase son elementos en ocasiones obviados por el alumnado, pero cuyo uso adecuado facilita mucho la comprensión).

\section{El software subtitulador}

Un problema con el que suele encontrarse el profesorado que quiere introducir la subtitulación activa en sus clases es la necesidad de contar con software para subtitular. El coste económico de este es un escollo para los centros educativos, puesto que comprar programas profesionales de pago, como podrían ser WinCaps, EZTitles, Spot o Fab, supone un fuerte gasto. Además, la licencia solo permite su uso dentro de las instalaciones, cuestión que condiciona el trabajo del alumnado, quien no puede practicar, por ejemplo, en casa. Otro aspecto a tener en cuenta es la interfaz de los programas, la cual no tiene que ser demasiado complicada, sobre todo si su usuario no está formándose como traductor profesional, sino

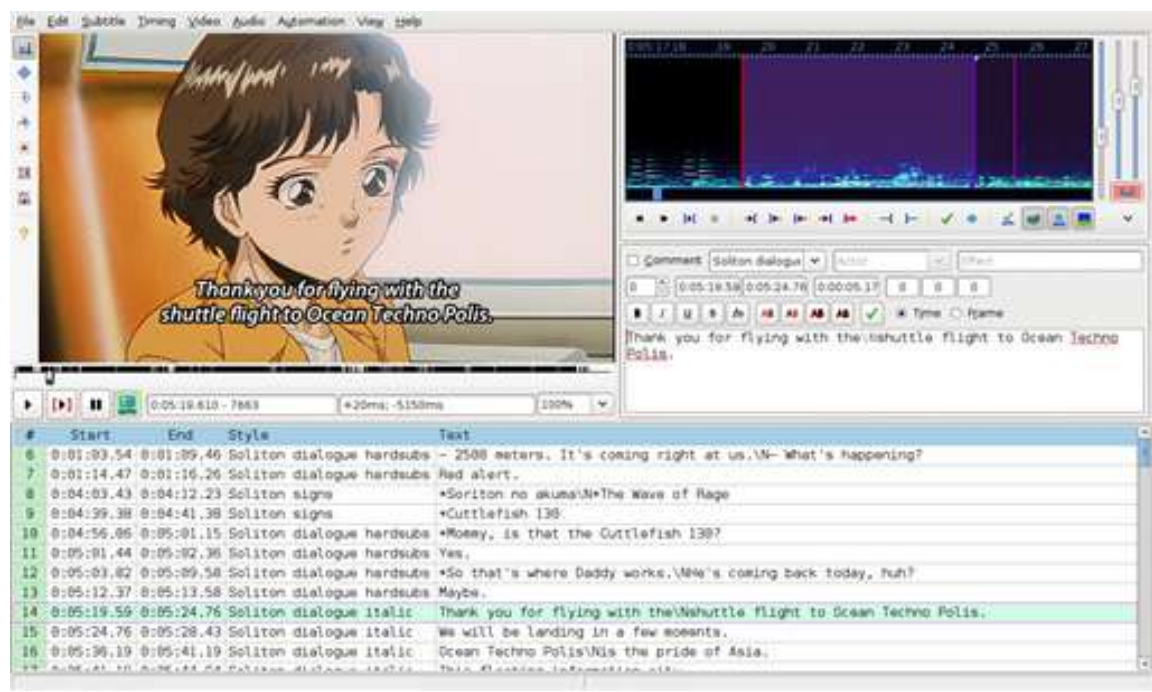

Figura 2 Interfaz de trabajo de Aegisub 
que simplemente hace un uso centrado en el aprendizaje de lenguas.

A principios del siglo XXI, en las aulas de subtitulación empezó a utilizarse uno de los programas que sigue estando entre los más populares: Subtitle Workshop. Este programa, desarrollado por URUsoft, ofrece una solución a las dos necesidades primordiales de la docencia en traducción: se puede descargar de manera libre desde la dirección de la propia empresa (http://subworkshop.sourceforge.net) y presenta una interfaz sencilla, de la que pueden destacarse aspectos como la facilidad para editar los códigos de tiempo de entrada y salida y el formato (ver Figura 1). Además, cuenta con tres espacios principales: el destinado a la pantalla del vídeo, en la parte superior, donde el alumnado puede observar de manera inmediata el resultado de su subtitulación; otro, en la zona central, formado por una barra de herramientas y un cuadro donde aparecen los subtítulos que se van creando numerados y acompañados por los códigos de tiempo; $y$, por último, en la parte inferior, aparecen dos recuadros donde editar tanto los códigos de tiempo como el texto de los subtítulos.

Un segundo programa muy utilizado en la formación de traductores, sobre todo de quienes se especializan en la subtitulación para sordos, es Aegisub (Figura 2).
Al igual que Subtitle Workshop, se puede descargar gratuitamente (www.aegisub.org) y resulta útil para cubrir algunas carencias del primero. De hecho, su creación se llevó a cabo en 2005, no como una herramienta de trabajo para subtituladores profesionales, sino para aficionados of fansubbers, cuyo trabajo suele alejarse de los parámetros oficiales de la subtitulación y se centra más en lo que suele ser su objetivo principal: acercar la cultura origen al espectador por medio de notas explicativas de los elementos culturales. Además, cuenta con un recuadro donde se observan las ondas de audio y que puede resultar un recurso muy útil a la hora de sincronizar los subtítulos con los diálogos del audio.

Los dos programas presentados, junto a otros como Subtitle Edit o VisualSubSync, están diseñados exclusivamente para la subtitulación, profesional oamateur, pero no para la enseñanza de lenguas, objetivo específico en cambio en el diseño de otro programa de subtitulación gratuito: LvS (Learning via Subtitling). La creación de este tipo de recursos vino patrocinada, no solo por la confianza en los beneficios de la subtitulación como herramienta activa, sino también por el relevante papel que iban adquiriendo las TIC en el mundo de la enseñanza (Hadzilacos, Papadakis y Sokoli, 2004). En el caso de LvS, su creación está ligada a un proyecto que, bajo el mismo nombre, patrocinó la Comisión Europea y que se desarrolló entre los años

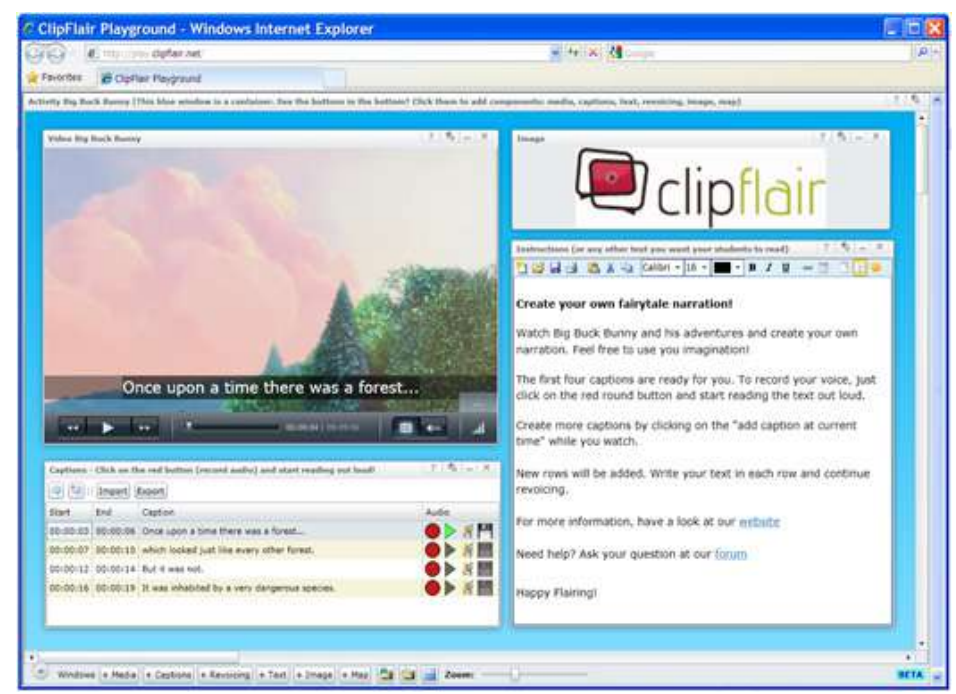

Figura 3 Interfaz de trabajo de Clipflair 


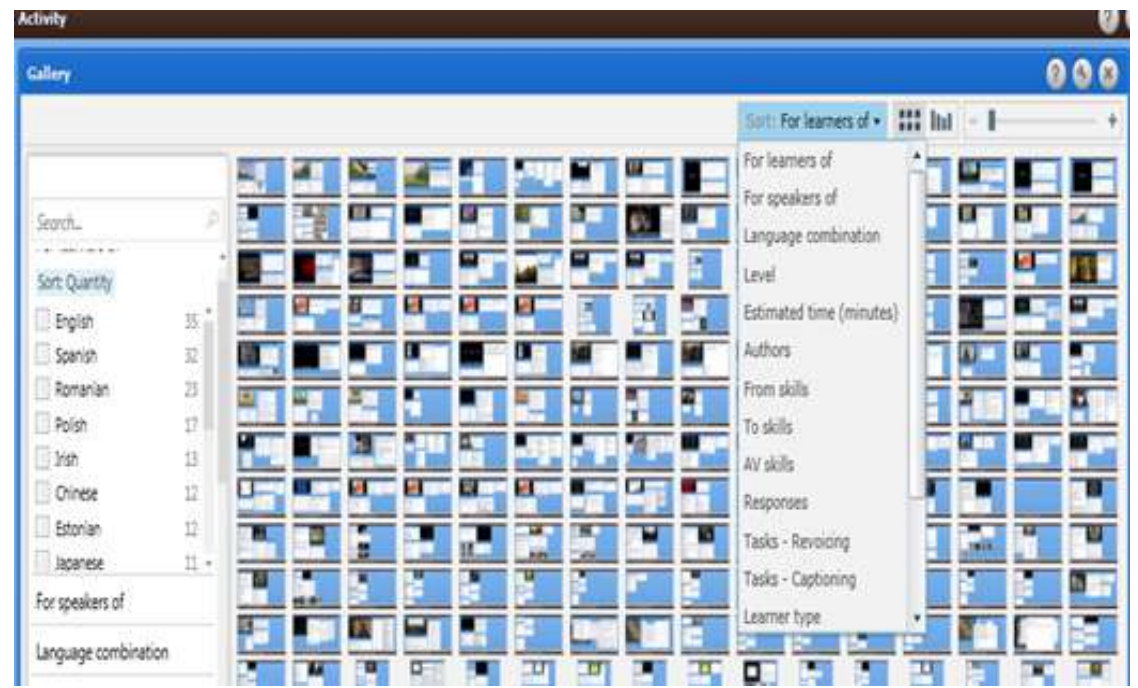

Figura 4 Interfaz de la galería de Clipflair

2006 y 2008 gracias al trabajo conjunto de varias universidades europeas. La principal novedad que ofrecía este tipo de software iba unida a su carácter eminentemente práctico y consistía en que, además de permitir la creación de subtítulos, reservaba parte de la interfaz para que el profesorado pudiera realizar anotaciones, produciéndose de este modo un diálogo virtual que facilitaba el trabajo a distancia.

ClipFlair (http://clipflair.net), por su parte, podría considerarse el heredero de LvS, ya que solucionaalgunas de las carencias de este y amplía sus posibilidades didácticas. Se trata de una plataforma desarrollada en el marco del programa europeo Lifelong Learning, cuyo objetivo es fomentar el aprendizaje de lenguas a partir de actividades basadas en modalidades de traducción audiovisual, principalmente el doblaje, la subtitulación y la audiodescripción (ver Figura 3).

La principal novedad la encontramos en la posibilidad de que los usuarios creen y cuelguen actividades, con distintos niveles de conocimientos lingüísticos en quince lenguas diferentes. ClipFlair propone un aprendizaje activo en el que los estudiantes pueden aprender de manera autónoma y a su ritmo, pero también proporciona herramientas colaborativas como foros y blogs (Sokoli, 2015, p. 130). La galería de la plataforma resulta de gran ayuda para el profesorado, ya que permite realizar un filtrado para encontrar las actividades más adecuadas dependiendo de variables, como combinación de idiomas que se desee utilizar, nivel lingüístico de los estudiantes o habilidades que se quieran trabajar (ver Figura 4).

La creación de ClipFlair ha supuesto un gran avance dentro de la enseñanza de lenguas mediante la traducción audiovisual y ha servido para establecer una enorme comunidad de usuarios que comparten materiales y ejercicios, lo cual permite dar respuesta a una de las demandas más habituales entre la comunidad educativa, aquella que hace referencia a la dificultad y la gran inversión de tiempo que supone preparar este tipo de actividades.

Por último, cabe añadir que este tipo de plataformas ha servido de germen para la creación de espacios similares como Pluritav (http://citrans.uv.es/pluri$\operatorname{tav} /$ ), un proyecto auspiciado por varias universidades españolas y británicas que apuesta por el enfoque multilingüe en la enseñanza de lenguas extranjeras y busca perfeccionar las competencias de todo el repertorio lingüístico del aula.

\section{Conclusión}

Desde el punto de vista del aprendizaje de lenguas, el visionado de productos subtitulados cuenta con la ventaja de ser un recurso que ayuda al espectador a entender los diálogos en una lengua que no conoce lo suficiente, pero, además, desde el punto de vista 
intralingüístico, sirve para consolidar la L1 del espectador (Díaz-Cintas, 2012, p. 103). Sin embargo, su uso únicamente implica beneficios de carácter pasivo y no permite que el receptor llegue a involucrarse en el proceso de aprendizaje. Esta carencia puede subsanarse con la introducción de actividades de creación de subtítulos en las aulas. Son numerosos los estudios que han demostrado que las diferentes variedades de subtítulos y la combinación de estas hacen de esta actividad un recurso que permite trabajar diferentes habilidades lingüísticas. De la misma forma, la plasticidad que presenta la subtitulación activa como herramienta didáctica posibilita adaptaciones por niveles o por aspectos que se quieran trabajar. Asimismo, el hecho traductor que implica su puesta en práctica conlleva el reconocimiento de elementos culturales, así como de lenguaje gestual y corporal, que permiten al profesorado presentar la actividad subtituladora como una técnica global, atractiva y con cierta utilidad social.

Todo esto, unido al papel de las nuevas tecnologías, imprescindible en este tipo de actividades, hacen de la subtitulación activa un ejercicio atractivo para el alumnado, el cual puede extrapolar su uso a parcelas de su vida cotidiana más lúdicas, como el consumo de material audiovisual subtitulado o, incluso, la subtitulación de productos que sean de su interés.

\section{Referencias}

Araújo, V. L. S. (2008). The educational use of subtitled films in EFL teaching. En J. Díaz Cintas (Ed.), The didactics of audiovisual translation (pp. 227-238). Ámsterdam/ Filadelfia: John Benjamins. https://doi.org/10.1075/ btl.77.22san

Baltova, I. (1999). The effect of subtitled and staged video input on the learning and retention of content and vocabulary in a second language. Tesis doctoral presentada en Ontario Institute for Studies in Education, University of Toronto. https://tspace.library.utoronto.ca/ bitstream/1807/13234/1/nq41096.pdf

Bean, R. M. y Wilson, R. M. (1989). Using closed captioned television to teach reading to adults. Reading Research and Instruction, 28(4), 27-37. https://doi. org/10.1080/19388078909557984
Bianchi, F. (2015). Subtitling science: An efficient task to learn content and language. Lingue e Linguaggi, 15, 20-25.

Bird, S. y Williams, J. (2002). The effect of bimodal input on implicit and explicit memory: An investigation into the benefits of within-language subtitling. Applied Psycholinguistics, 23(4), 509-533. https://doi.org/10.1017/ s0142716402004022

Birulés-Muntané, J. y Soto-Faraco, S. (2016). Watching subtitled films can help learning foreign languages. PLoS one, 11(6). https://doi.org/10.1371/journal. pone.0158409

Bolaños-García-Escribano, A. (2017). The effects of fansubs on EFL education for translation and interpreting students: an empirical approach. The Journal of Specialised Translation, 28. https://www.jostrans.org/issue28/ art_bolanos.pdf

Borghetti, C. y Lertola, J. (2014). Interlingual subtitling for intercultural language education: A case study. Language and Intercultural Communication, 14(4), 423-440. https://doi.org/10.1080/14708477.2014.934380

Borrás, I.yLafayette, R. (1994).Effects of multimediacourseware subtitling on the speaking performance on college students of French. The Modern Language Journal, 78(1), 61-75. https://doi.org/10.1111/j.1540-4781.1994. tb02015.x

Bravo, C. (2008). Putting the reader in the picture: Screen translation and foreign-language learning. Tesis doctoral presentada en la Universitat Rovira i Virgili, Tarragona.

Burczyńska, P. (2015). Reversed subtitles as a powerful didactic tool in sLA. En Y. Gambier, A. Caimi, y C. Mariotti (Eds.), Subtitles and language learning (pp. 221-244). Berna: Peter Lang. https://doi. org/10.3726/978-3-0351-0719-7

Caimi, A. (2006). Audiovisual translation and language learning: The promotion of intralingual subtitles. The Journal of Specialised Translation, 6, 85-98.

Carreres, Á. (2006). “Strange bedfellows: Translation and language teaching. The teaching of translation into L2 in modern languages degrees: Uses and limitations". $6^{\text {th }}$ Symposium on Translation, Terminology and Interpretation in Cuba and Canada. http://www.cttic.org/ ACTI/2006/papers/Carreres.pdf

Chaume, F. (2003). Doblatge i subtitulació per a la TV, Vic: Eumo.

Chaume, F. (2004). Cine y traducción. Madrid: Cátedra.

Cook, V. (2001). Using the first language in the classroom. The Canadian Modern Language Review, 57, 402-423. https://doi.org/10.3138/cmlr.57.3.402 
Cummins, J. (2007). Rethinking monolingual instructional strategies in multilingual classrooms. Canadian Journal of Applied Linguistics/Revue canadienne de linguistique appliquée, 10(2), 221-240.

D’Ydewalle, G. y Gielen I. (1992). Attention allocation with overlapping sound, image and text. En Rayner, K. (Ed.), Eye movements and visual cognition: Scene perception and reading (pp. 415-427). Nueva York, Estados Unidos: Springer Verlag. https://doi. org/10.1007/978-1-4612-2852-3_25

D’Ydewalle, G., Muylle, P. y Van Rensbergen, J. (1985). Attention shifts in partially redundant information situations. En Groner, R., McConkie, G.W. y Menz, C. (Eds.), Eye movements and human information processing (pp. 375-384). Ámsterdam: Elsevier Science Publishers B.V. (North-Holland).

D’Ydewalle, G. y van Rensbergen, J. (1989). Developmental studies of text-picture interactions in the perception of animated cartoons with texts. En Mandl, H. y Levin, J. R. (Eds.), Knowledge acquisition from text and pictures (pp. 233-248). Ámsterdam, Holanda: Elsevier/North Holland. https://doi.org/10.1016/ s0166-4115(08)62157-3

Danan, M. (1992). Reversed subtitling and dual coding theory: New directions for foreign language instruction. Language Learning, 42(4), 497-527. https://doi. org/10.1111/j.1467-1770.1992.tb01042.x

Danan, M. (2004). Captioning and subtitling: Undervalued language learning strategies. Meta, 49(1), 67-77. https://doi.org/10.7202/009021ar

Diao, Y., Chandler, P. P. y Sweller, J. (2007). The effect of written text on comprehension of spoken English as a foreign language. The American Journal of Psychology, 120(2), 237-261. https://doi.org/10.2307/20445397

Díaz Cintas, J. (1995). El subtitulado como técnica docente. Vida Hispánica, 12, 10-14.

Díaz Cintas, J. (2010). Subtitling. En Y. Gambier y L. Van Doorslaer. (Eds.), Handbook of translation studies (pp. 344-349). Manchester: St. Jerome.

Díaz Cintas, J. (2012). Los subtítulos y la subtitulación en la clase de lengua extranjera. Abehache, Revista da Associação Brasileira de Hispanistas, 3, 95-114.

Díaz Cintas, J. y Muñoz Sánchez, P. (2006). Fansubs: Audiovisual translation in an amateur environment. Journal of Specialised Translation, 6, 37-52.

Ellsworth, T. (1992). Waiter, a dish of satellite, please!: Integrating subtitled video into your teaching, English Teaching Forum, 30(3), 24-27.
Gambier, Y. (2007). Sous-titrage et apprentissage des langues. En Neves, J. y Remael, A. (Eds.), Linguistica Antverpiensia, 6, 97-113.

Garza, T. (1991). Evaluating the use of captioned video materials in advanced foreign Language learning. Foreign Language Annals, 24(3), 239-258. https://doi. org/10.1111/j.1944-9720.1991.tb00469.x

Gernsbacher, M. A. (2015). Video captions benefit everyone. Policy Insights from the Behavioral and Brain Sciences, 2(1), 195-202. https://doi. org/10.1177/2372732215602130

Goldman M. y Goldman, S. (1988). Reading with closedcaptioned TV. Journal of Reading, 31(5), 458-461.

Gómez Pérez, M. C. y Roales Ruiz, A. (2011). Uso didáctico de la subtitulación en la clase de lengua C. En S. Roiss, C. Fortea Gil, M. Á. Recio Ariza, B. Santana, P. Zimmermann y I. Holl (Eds.), En las vertientes de la traducción e interpretación del/al alemán (pp. 201212). Berlín: Frank \& Timme GmbH. https://doi. org/10.3726/978-3-653-05424-8/41

González-Iglesias, J. D. (2012). Desarrollo de una herramienta de análisis de los parámetros técnicos de los subtitulos y estudio diacrónico de series estadounidenses de televisión en DVD. Tesis doctoral presentada a la Universidad de Salamanca. https://doi.org/10.14201/gredos.121168

Hadzilacos, T., Papadakis, S. y Sokoli, S. (2004). Learner's version of a professional environment: Film subtitling as an ICTE tool for foreign language learning. En G. Richards (Ed.), Proceedings of world conference on e-learning in corporate, government, healthcare, and higher education (pp. 680-658). Chesapeake, vA: AACE.

Huang, H. C. y Eskey, D. E. (1999). The effects of closed-captioned television on the listening comprehension of intermediate English as a second language (ESL) students. Journal of Educational Technology Sustems, 28(1), 75-96. https://doi.org/10.2190/rg06-lywb-216y-r27g

Incalcaterra McLoughlin, L. (2009). Subtitles in translators' training:Amodelofanalysis.RomanceStudies, 27(3),174185. https://doi.org/10.1179/174581509x455141

Incalcaterra McLoughlin, L., \& Lertola, J. (2014). Audiovisual translation in second language acquisition: Integrating subtitling in the foreign language curriculum. Special issue of The Interpreter and Translator Trainer, 8(1), 7083. https://doi.org/10.1080/1750399X.2014.908558

Incalcaterra McLoughlin, L. y Lertola, J. (2016). Captioning and revoicing of clips in foreign language learningusing clipflair for teaching Italian in online learning environments. En C. Ramsey-Portolano (Ed.), The future of Italian teaching (pp. 55-69). Newcastle upon Tyne: Cambridge Scholars Publishing. 
Ivarsson, J. (1992). Subtitling for the media. Estocolmo: Ljunglöfs Offset $\mathrm{AB}$.

Kantz, D. (2015). Multimodal subtitling -A medical perspective. En Y. Gambier, A. Caimi y C. Mariotti (Eds.), Subtitles and language learning. Principles, strategies and practical experiences (pp. 269-292). Berna: Peter Lang. https://doi.org/10.14746/gl.2016.43.1.14

Karamitroglou, F. (1998). A proposed set of subtitling standards in Europe. Translation Journal 2(2). http:// translationjournal.net/journal/04stndrd.htm

Koolstra, C. M. y Beentjes, J. W. J. (1999). Children's vocabulary acquisition in a foreign language through watching subtitled television programmes at home. Educational Technology Research \& Development, 47(1), 51-60. https://doi.org/10.1007/bf02299476

Koskinen, P., Knable, J., Markham, P., Jensema, C. y Kane, K. (1996). Captioned television and the vocabulary acquisition of adult second language correctional facility residents. Journal of Educational Technology Systems, 24, 359-373. https:// doi.org/10.2190/jkc2-le5d-36bc-809f

Kothari, B. y Bandyopadhyay, T. (2011). Can India's literate read? International Review of Education, 56(5/6), 705-

Kothari, B. y Bandyopadhyay, T. (2014). Same language subtitling of Bollywood Film songs on TV: Effects on literacy. Information Technologies \& International Development, 10(4), 31-47. http://itidjournal.org/ index.php/itid/article/view/1307/502

Kothari, B., Pandey, A. y Chudgar, A. R. (2004). Reading out of the 'idiot box': same language subtitling on $\mathrm{TV}$ in India. Information Technologies and International Development, 2(1), 23-44. https://doi. org/10.1162/1544752043971170

Krashen, S. (1982). Principles and practice in second language acquisition. Nueva York: Pergamon Press.

Krashen, S. (1987). Principles and practice in second language acquisition. Exeter: Prentice-Hall International.

Lambert W. E. y Holobow, N. E. (1984). Combinations of printed script and spoken dialogue that show promise for beginning students of a foreign language. Canadian Journal of Behavioural Science/Journal Canadien des Sciences du Comportement, 16, 1-11. https://doi. org/10.1037/h0080775

Lambert, W. E., Boehler, I. y Sidoti, N. (1981). Choosing the languages of subtitles and spoken dialogues for media presentations: Implications for second language education. Applied Psycholinguistics, 2(2), 133-148. https://doi.org/10.1017/s0142716400000904
Lertola, J. (2012). The effect of subtitling task on vocabulary learning. En A. Pym y D. Orrego-Carmona (Eds.), Translation research projects 4 (pp. 61-70). Tarragona, España: Intercultural Studies Group.

Lertola, J. (2013). Subtitlingnew media: Audiovisual translation and second language acquisition. Tesis doctoral presentada en la National University of Ireland, Galway.

Lertola, J. (2015). Subtitling in language learning: Suggestions for language teachers. En Y. Gambier, A. Caimi y C. Mariotti (Eds.), Subtitles and language learning (pp. 245-267). Berna: Peter Lang. https:// doi.org/10.3726/978-3-0351-0719-7

Lertola, J. (2019). Audiovisual translation in the foreign language classroom: Applications in the teaching of English and other foreign languages. Voillans: Research-publishing.net. https://doi.org/10.14705/ rpnet.2019.27.9782490057252

Lertola, J. y Mariotti, C. (2017). Reverse dubbing and subtitling: Raising pragmatic awareness in Italian ESL Learners. JoSTrans-The Journal of Specialised Translation, 28, 103-121.

López Cirugeda, I. y Sánchez Ruiz Universidad De CastillaLa, R. (2013). Subtitling as a didactic tool. A teacher training experience. Porta Linguarum, 20, 45-62.

Lopriore, L., \& Ceruti, M. A. (2015). Subtitling and language awareness: a way and ways. En Y. Gambier, A. Caimi \& C. Mariotti (Eds), Subtitles and language learning (pp. 293-321). Peter Lang. https://doi. org/10.3726/978-3-0351-0719-7

Malmkjaer, K. (1998). Translation and language teaching. Manchester: St Jerome.

Markham, P. (1989). The effects of captioned videotapes on the listening comprehension of beginning, intermediate, and advanced ESL students. Educational Technology, 29(10), 38-41.

Marzà, A. y Torralba G. (2015). Incidental language learning through subtitled cartoons: Is it possible in a dubbing country? En Gambier, Y., Caimi, A. y Mariotti, C. (Eds.), Subtitles and language learning (pp. 199-220). Berna: Peter Lang. https://doi. org/10.3726/978-3-0351-0719-7

Neuman, S. y Koskinen, P. (1992). Captioned television as comprehensible input: Effects of incidental word learning in context for language minority students. Reading Research Quarterly, 27(1), 94-106. https:// doi.org/10.2307/747835

Neves, J. (2004). Language awareness through training in subtitling. En Orero, P. (Ed.), Topics in audiovisual 
translation (pp. 127-139). Ámsterdam: John Benjamins. https://doi.org/10.1075/btl.56.14nev

Parlato, S. (1986). Watch your language: Captioned media for literacy. Silver Spring, MD: T. J. Publishers.

Pavakanun, U. y d'Ydewalle, G. (1992). Watching foreign television programs and language learning. En Engel, F. L., Bouwhuis, D. G. y d'Ydewalle, G. (Eds.), Cognitive modelling and interactive environments in language learning (pp. 193-198). Berlín: Springer. https://doi. org/10.1007/978-3-642-77575-8_24

Perego, E y Ghia, E. (2011). Subtitles consumption according to eye tracking data. En Incalcaterra McLoughlin, L., Biscio M. y Ní Mhainnín, M. Á. (Eds.), Audiovisual translation:Subtitles and subtitling. Theory and practice. New Trends in Translation Studies, 9 (pp. 177196). Berna/Frankfurt: Peter Lang. https://doi. org/10.3726/978-3-0353-0167-0

Rees, T. (1993). Closed captions in the classroom. Artículo inédito. Northampton, MA: International Language Institute of Massachusetts.

Reig Gascón, A. (2017). Pedagogical translation, subtitles and ICTs: Collaborative projects in L2 classroom. Lenguaje y textos, 46, 115-123. http://doi. org/10.4995/lyt.2017.7440

Romero-Fresco, P. (2009). More haste less speed: Edited vs verbatim respeaking. Vigo International Journal of Applied Linguistics (VIAL), VI, 109-133.

Ryan, S. (1998). Using films to develop learner motivation, The Internet TESL Journal, 4(11). http://iteslj.org/ Articles/Ryan-Films.html

Sokoli, S. (2006). Learning via subtitling (LvS). A tool for the creation of foreign language learning activities based on film subtitling. Actes MuTra 2006 - Multidimensional translation: Audiovisual translation scenarios, Copenhague: University of Copenhagen. https://doi.org/10.1057/9780230234581_3

Sokoli, S. (2015). ClipFlair: Foreign language learning through interactive revoicing and captioning of clips. En Y. Gambier, A. Caimi y C. Mariotti (Eds.), Subtitles and language learning (pp. 127-148). Berna: Peter Lang. https://doi.org/10.3726/978-3-0351-0719-7

Sokoli, S., Zabalbeascoa, P. y Fountana, M. (2011). Subtitling activities for foreign language learning: What learners and teachers think. En L. Incalcaterra McLoughlin, M. Biscio, y M. Á. Ní Mhainnín (Eds.), Audiovisual translation: Subtitles and subtitling. Theory and practice. New trends in translationstudies, 9(pp.219-242).Berna/Frankfurt,
Suiza, Alemania: Peter Lang. https://doi. org/10.3726/978-3-0353-0167-0

Talaván, N. (2006). Using subtitles to enhance foreign language education. Porta Linguarum, 6, 41-52. http://www.ugr.es/ portalin/articulos/PL_numero6/indice.pdf

Talaván, N. (2007). Learning vocabulary through authentic video and subtitles. TESOL-Spain Newsletter, 31, 5-8.

Talaván, N. (2010). Subtitling as a task and subtitles as support: Pedagogical applications. En J. Díaz Cintas, A. Matamala, y J. Neves (Eds.), New insights into audiovisual translation and media accessibility (pp. 285-299). Ámsterdam: Rodopi. https://doi. org/10.1163/9789042031814_021

Talaván, N. (2011). A quasi-experimental research project on subtitling and foreign language acquisition. En L. Incalcaterra McLoughlin, M. Biscio, y M. Á. Ní Mhainnín (Eds.), Audiovisual translation subtitles and subtitling. Theory and practice (pp. 197-217). Berna: Peter Lang. https://doi. org/10.3726/978-3-0353-0167-0

Talaván, N. (2013). La subtitulación en el aprendizaje de lenguas extranjeras. Barcelona: Octaedro. https://doi. org/10.1353/hpn.2014.0049

Talaván, N. y Ávila-Cabrera, J. (2015). First insights into the combination of dubbing and subtitling as L2 didactic tools. En Y. Gambier, A. Caimi, y C. Mariotti (Eds.), Subtitles and language learning (pp. 149-172). Berna: Peter Lang.

Talaván, N., Lertola, J. y Costal, T. (2016). iCap: Intralingual captioning for writing and vocabulary enhancement. Alicante Journal of English Studies, 29, 229-247. https://doi.org/10.14198/raei.2016.29.13

Talaván, N., Ibáñez, A., y Bárcena, E. (2017). Exploring collaborative reverse subtitling for the enhancement of written production activities in English as a second language. ReCALL, 29(1), 39-58. https://doi. org/10.1017/S0958344016000197

Talaván, N. y Rodríguez-Arancón, P. (2014). The use of reverse subtitling as an online collaborative language learning tool. The Interpreter and Translator Trainer, $8(1), \quad 84-101$. https://doi.org/10.1080/175039 9x.2014.908559

Torralba, G. (2016). L'aprenentatge de llengües a través de la traducció audiovisual: la subtitulació com a eina per a l'adquisició de lèxic en llengua estrangera. Tesis doctoral presentada en la Universitat Jaume I de Castellón de la Plana (España). https://doi. org/10.6035/12211.2016.55154 
Torralba, G. (2018): Aprendizaje y perfeccionamiento de lenguas: la subtitulación en el grado en maestro de educación primaria. Revista de Lenguas para Fines Especificos, 24(2), 73-91. https://doi.org/10.17979/ digilec.2016.3.0.1751

Vanderplank, R. (1988). The value of teletext sub-titles in language learning. ELT Journal, 4(4), 272-281. https://doi.org/10.1093/elt/42.4.272

Vanderplank, R. (2016). Captioned media in foreign language learning and teaching. Subtitles for the deaf and hard-of-hearing as tools for language learning. Londres: Palgrave Macmillan. https://doi. org/10.1057/978-1-137-50045-8

Vermeulen, A. (2003). La traducción audiovisual en la enseñanza de idiomas. Actas del segundo congreso internacional de español para fines especificos, 159-168. https://doi. org/10.17855/jlas.2014.02.33.1.3
Wagener, D. (2006). Promoting independent learning skills using video on digital language laboratories. Computer Assisted Language Learning, 19(4-5), 279-286. https://doi.org/10.1080/09588220601043180

Williams, H. y Thorne, D. (2000). The value of teletext subtitling as a medium forlanguage learning. System, 28(2), 217-228. https://doi.org/10.1016/ s0346-251x(00)00008-7

Winke, P. P., Gass, S. y Sydorenko, T. (2010). The effects of captioning video for foreign language listening activities. Language Learning and Technology, 14(1), 65-86.

Yuste Frías, J. (2005). Didáctica de la traducción inversa español-francés: el fin justifica los medios. En J. Yuste Frías y A. Álvarez Lugrís (Eds.), Estudios sobre traducción: teoria, didáctica, profesión (pp. 147-170). Vigo: Servizo de Publicacións da Universidade de Vigo. https://doi. org/10.5209/estr.57463

How to reference this article: Torralba-Miralles, Gloria (2020). El uso de los subtítulos pasivos y activos en la enseñanza de lenguas extranjeras: una revisión de las posibilidades didácticas de ambos recursos Íkala, Revista de Lenguaje y Cultura, 25(1), 231-250, http://www.doi.org/10.17533/udea.ikala. v25n01a11 